\title{
Bayesian uncertainty analyses of Great Barrier Reef catchment water quality model parameters without likelihood assumptions
}

\author{
$\underline{\text { R. Baheerathan and F. R. Bennett }}$ \\ Queensland Department of Natural Resources, Mines and Energy, Dutton Park \\ Email: Ramanan.Baheerathan@dnrme.qld.gov.au
}

\begin{abstract}
Catchment water quality modelling is used as part of the Paddock to Reef program to assess the impact of land management changes across the Great Barrier Reef (GBR) catchments against water quality targets. It is necessary to have confidence in model performance in order to use them effectively for management and decision-making. Thus calibration, uncertainty and sensitivity analyses of model parameters are critical to optimise their predictive capability and thereby help facilitate better targeting of improved management practices.
\end{abstract}

Average annual loads estimated at end-of-systems (EOS) sites are likely to represent cumulative effects of various water quality processes. As a result, the calibration and uncertainty analyses of model parameters becomes a challenge.

Employed together, adaptive Sequential Monte Carlo sampled Approximate Bayesian Computation (SMC$\mathrm{ABC}$ ) and machine learning trained surrogate models offer an efficient framework for the calibration and uncertainty analyses of water quality model parameters. The appealing feature of Approximate Bayesian Computation when compared to formal Bayesian analysis is that it overcomes the requirement for an explicit likelihood function. As a compromise, an empirical approach is employed to stochastically sample from the unknown likelihood. This process can be computationally expensive when samples require the evaluation of a numerical models such as a catchment water quality model. To overcome this burden, machine learning techniques can be used to synthesise and train an efficient surrogate model to substitute for the functionality of the primitive model in the $\mathrm{ABC}$ algorithm.

This paper demonstrates the application of this combination of technologies for the calibration and uncertainty analyses of parameters that represent the transport of fine-sediment and particulate nutrients in two GBR basins namely the Pioneer River and Sandy Creek basins.

The comparison between fine-sediment streambank erosion estimated by the selected model along the O'Connell River between 2010 and 2014 against that estimated by the O'Connell River stability assessment (ORSA) was encouraging. Estimate by the selected calibrated model was only $1.6 \%$ greater than the ORSA estimate.

Average annual fine-sediment and particulate nutrient loads estimated by the calibrated model at the Pioneer River EOS site were within $+/-9 \%$ of that estimated by the GBR catchment loads monitoring program (GBRCLMP). Average annual fine-sediment and particulate nutrient loads estimated by the calibrated model at Sandy Creek EOS site are within +/- 3\% of that estimated by GBRCLMP. Analysis of model parameter uncertainty reveals that all GBRCLMP estimated average annual constituent loads lie within the $95 \%$ credibility intervals of the modelled data.

This work demonstrates that employed together, SMC-ABC and machine learning trained surrogate models offer an efficient and powerful framework for the calibration and uncertainty analyses of GBR water catchment quality model parameters.

Keywords: Water quality modelling, calibration, uncertainty, approximate Bayesian computation 
Baheerathan et al., Bayesian uncertainty analyses of Great Barrier Reef catchment water quality model parameters

\section{INTRODUCTION}

Catchment water quality modelling is used as one of multiple lines of evidence to report on progress towards Great Barrier Reef (GBR) Reef 2050 Plan (Reef Plan) (Anon 2018) water quality targets. Within the Paddock to Reef (P2R) program, the Source Catchments modeling framework is used to construct GBR specific models (McCloskey, 2017) and the overarching purpose of the modeling is to assess the impact of land management changes across the GBR against Reef Plan targets.

It is necessary to have confidence in model performance in order to use them effectively for management and decision-making. Thus calibration and uncertainty analyses of GBR water quality model parameters are critical to optimize their predictive capability as well as quantify their uncertainty and thereby help facilitate better targeting.

Average annual loads estimated as part of P2R program are being used to improve the performance of GBR catchment water quality models. This water quality data collected at end-of-systems (EOS) sites, located downstream of multiple land uses, are likely to represent cumulative effects of various water quality processes. As a result, the calibration and uncertainty analyses of model parameters becomes a necessary challenge.

Employed together, adaptive sequential Monte Carlo Approximate Bayesian Computation (SMC-ABC) and machine learning trained surrogate models offer an efficient framework for the calibration and uncertainty analyses of GBR catchment water quality model parameters. This paper demonstrates the application of this method for the calibration and uncertainty analyses of parameters that represent the transport of fine-sediment and particulate nutrients in the Pioneer River and Sandy Creek basins of the Mackay-Whitsunday natural resource management region.

\section{METHODS}

\subsection{Overview}

The Reef 2050 Long Term Sustainability Plan (Anon 2018) requires the modelling of various water quality constituents, including fine-sediment, particulate nutrients (nitrogen and phosphorus), dissolved nutrients and agrochemicals. Given these requirements, the GBR Source Catchments models are configured to model various water quality process representations at a daily timestep over a 28 year time frame (McCloskey et al. 2017).

Dynamic SedNet (DS) (Ellis 2017), a GBR Source Catchments 'plug-in' developed to assist the GBR catchment modelling program, was used to simulate the supply of fine-sediment and particulate nutrients from major sources and their losses at various sinks: including:

- streambank, hillslope, and gully erosion;

- in-stream and floodplain deposition and remobilisation; and

- storage trapping.

Table 1. Parameters chosen to represent water quality processes of fine-sediment and particulate nutrients with parameter ranges used in the Bayesian analysis.

\begin{tabular}{|l|l|l|l|}
\hline Parameter & Label & Water quality process & Range \\
\hline $\begin{array}{l}\text { Delivery ratio in } \\
\text { conservation and forestry }\end{array}$ & DR1 & $\begin{array}{l}\text { supply from hillslope erosion in conservation and forestry land } \\
\text { uses }\end{array}$ & $0-50 \%$ \\
\hline Delivery ratio in grazing & DR2 & $\begin{array}{l}\text { fine-sediment supply from hillslope erosion in open and closed } \\
\text { grazing land uses }\end{array}$ & $0-50 \%$ \\
\hline $\begin{array}{l}\text { Delivery ratio in } \\
\text { sugarcane }\end{array}$ & DR3 & fine-sediment supply from hillslope erosion in sugar cane land use & $0-50 \%$ \\
\hline Gully delivery ratio & DR4 & fine-sediment supply from gully erosion. & $0-50 \%$ \\
\hline Bank erosion coefficient & BEC & fine-sediment supply from streambank erosion. & $1 \mathrm{E}-5-5 \mathrm{E}-5$ \\
\hline $\begin{array}{l}\text { Floodplain deposition } \\
\text { velocity }\end{array}$ & FPD & fine-sediment loss to floodplain deposition & $1 \mathrm{E}-6-5 \mathrm{E}-2 \mathrm{~m} / \mathrm{s}$ \\
\hline $\begin{array}{l}\text { Channel deposition } \\
\text { velocity }\end{array}$ & CD & fine-sediment loss to channel deposition & $1 \mathrm{E}-6-1 \mathrm{E}-2 \mathrm{~m} / \mathrm{s}$ \\
\hline $\begin{array}{l}\text { Channel remobilisation } \\
\text { velocity }\end{array}$ & CR & fine-sediment supply from channel remobilisation & $0-1 \mathrm{~m} / \mathrm{s}$ \\
\hline $\begin{array}{l}\text { Particulate nitrogen } \\
\text { enrichment ratio }\end{array}$ & PNER & $\begin{array}{l}\text { enrichment of particulate nitrogen due to preferential bonding with } \\
\text { fine-sediments }\end{array}$ & $1-5$ \\
\hline $\begin{array}{l}\text { Particulate phosphorous } \\
\text { enrichment ratio }\end{array}$ & PPER & $\begin{array}{l}\text { enrichment of particulate phosphorous due to preferential bonding } \\
\text { with fine-sediments }\end{array}$ & $1-5$ \\
\hline
\end{tabular}


Model parameters representative of key water quality processes of fine-sediment and particulate nutrients transport (see Table 1) were chosen for the calibration and uncertainty analyses exercise.

\subsection{SMC-ABC and machine learning trained surrogate modelling}

The aim of $\mathrm{ABC}$ is to sample from a posterior that is conditioned by observational data without any reference to likelihood functions. This is achieved by replacing the likelihood term in the familiar Bayes equation

$$
p(\theta \mid D) \propto p(D \mid \theta) p(\theta)
$$

by a comparison between observed $(D)$ and model simulated data expressed in terms of a summary statistic as shown in (2)

$$
p(\theta \mid D)_{\epsilon} \propto \int M(\boldsymbol{y} \mid \theta) \mathbb{1}(\rho(S(\boldsymbol{y}), S(D)) \leq \epsilon) p(\theta) d \boldsymbol{y}
$$

where $M$ is a model that given parameters $\theta$ generates the simulated data $\boldsymbol{y} . \rho(S(\boldsymbol{y}), S(D))$ is a distance metric comparing the summary statistic evaluated for the simulated and observed data and $\epsilon$ is the acceptance tolerance. In principal, when the tolerance is small enough $p(\theta \mid D)_{\epsilon}$ becomes a good estimate of the true Bayesian posterior. The canonical $\mathrm{ABC}$ algorithm is based on simple rejection sampling and is analogous in many ways to the Generalised Likelihood Uncertainty Estimation (GLUE) (Sadegh and Vrugt 2013; Nott et al. 2012). One of the concerns of the $A B C$ rejection algorithm however, is that the sampling efficiency can be very inefficient for small threshold values when the Bayesian prior is considerably divergent from the posterior parameter distribution. Sequential Monte Carlo-ABC attempts to remedy this problem to some extent.

SMC-ABC (Toni et al. 2009) provides a means by which a sequence of decreasing tolerance levels can be efficiently explored in a systematic fashion. A more detailed discussion of the SMC-ABC algorithm along with relevant references can be found in a companion to this paper within the current conference proceedings (Bennett 2019) and won't be further developed here.

The summary statistic, $S$, is a function of the model output $\boldsymbol{y}$ and needs to be evaluated for each sample drawn from the prior for testing as in (2). Typically, to generate a sufficient number of samples from the posterior, hundreds of thousands or even millions of model evaluations are required. The catchment water quality models developed for the GBR program can take between 15 minutes and 2 hours to run so even in with a highperformance computing environment, the computational effort to do $\mathrm{ABC}$ parameter inference based on primitive models would be overwhelming.

A practical alternative is to build a surrogate model to emulate the evaluation of the summary statistic as a function of the random variable $\theta$. Machine learning based regression methods are strong candidates for this purpose and have been applied to this task elsewhere (Cui et al. 2018). There are many machine learning techniques available but an agnostic, automatic machine learning approach has been used for this work.

The Tree-Based Pipeline Optimisation Tool (TPOT) (Olson et al. 2016) is a Python library that implements a genetic optimiser that constructs machine learning pipelines. TPOT automates the tasks of feature engineering, model selection and stacking and parameter optimization to finally export a model to code that can then be easily re-used as an emulator engine replacing the original model once suitable training data has been assembled.

\subsection{Data}

\section{O'Connell River Stability Assessment}

The O'Connell River stability assessment (ORSA) was undertaken to estimate sediment supply due to streambank erosion from major erosion sites along five different reaches in the O'Connell River (Ivesich et al. 2014). The volumes of sediment eroded between 2010 and 2014 along those reaches (Figure 1) were estimated using digital elevation models (DEMs) derived from LiDAR data sets acquired in those years. From the 2010 and 2014 DEMs, a DEM of Difference (DOD) was developed to estimate volumes of sediment eroded at a specific location at different points in time.

In order to compare against the modelled fine-sediment streambank erosion, the ORSA derived volumes of total sediment supply along the reaches were multiplied by the clay and silt proportion applied at the same location in the DS catchment model. 
The 'bank erosion coefficient' parameter that was chosen to represent stream bank erosion process was calibrated by reducing the bias between the modelled fine-sediment supply along all five reaches and that was estimated by the ORSA.

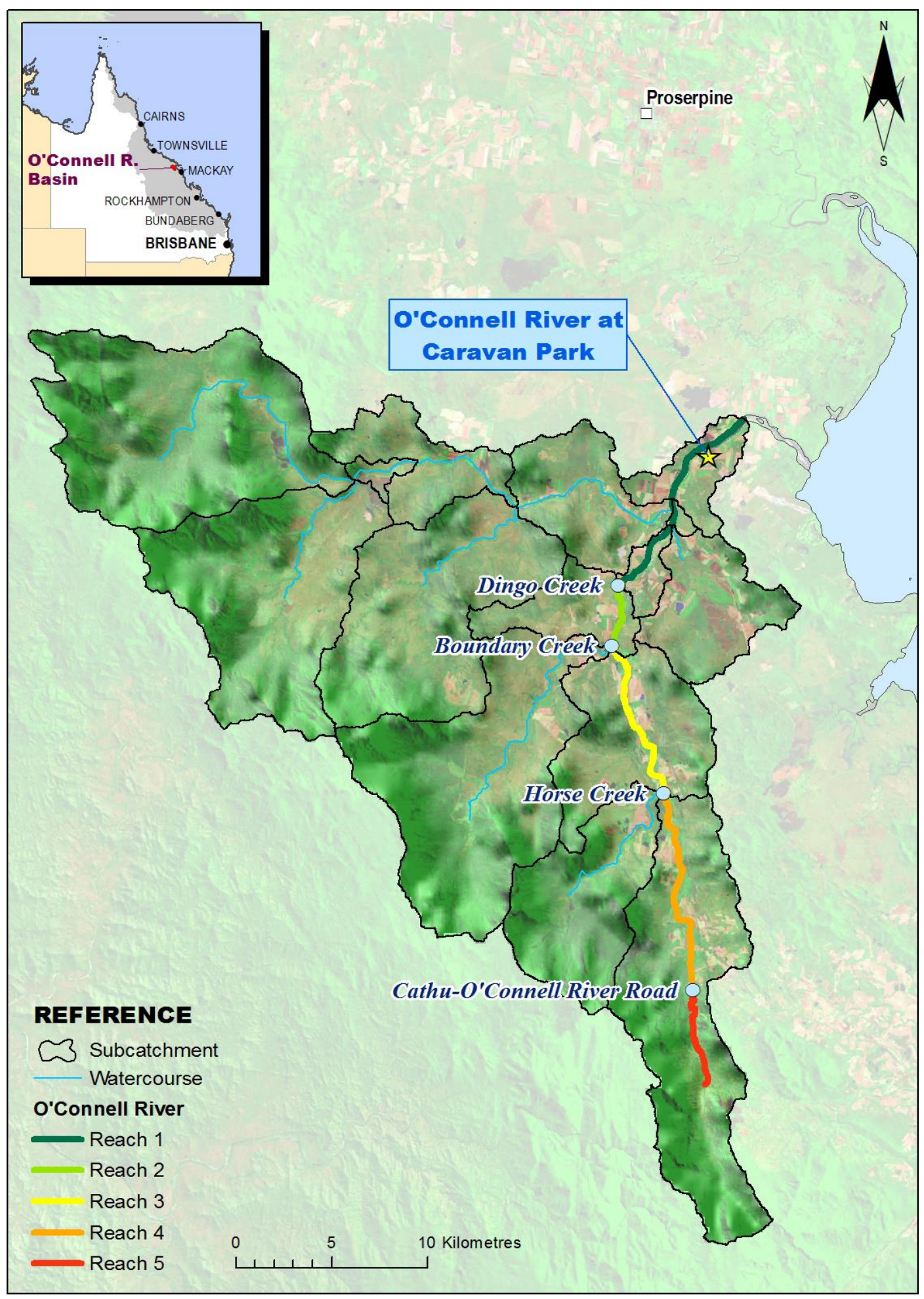

Figure 1. Five reaches along the O'Connell River. 


\section{Average annual loads}

Annual loads of various water quality constituents, including fine-sediment and particulate nutrients are being estimated as part of the Great Barrier Reef Catchment Loads Monitoring Program (GBRCLMP) at end-ofsystem (EOS) sites of the Pioneer River and Sandy Creek basins in the Mackay-Whitsunday natural resource management region (Turner et al. 2013). Model parameters selected to represent water quality processes (except streambank erosion) were calibrated by reducing bias between modelled average annual loads and that was estimated by GBRCLMP at both EOS sites.

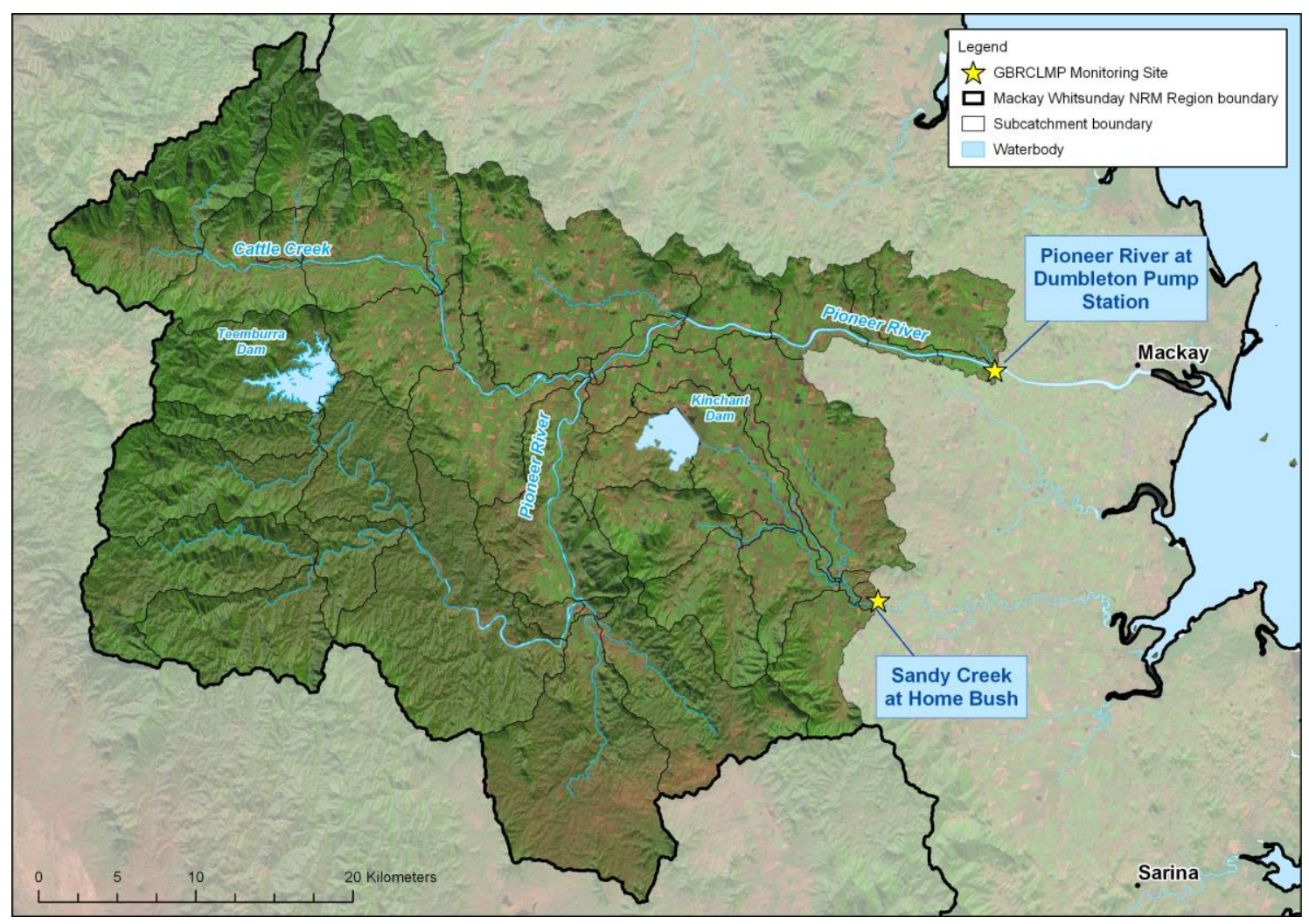

Figure 2. GBRCLMP EOS Monitoring sites.

\section{RESULTS}
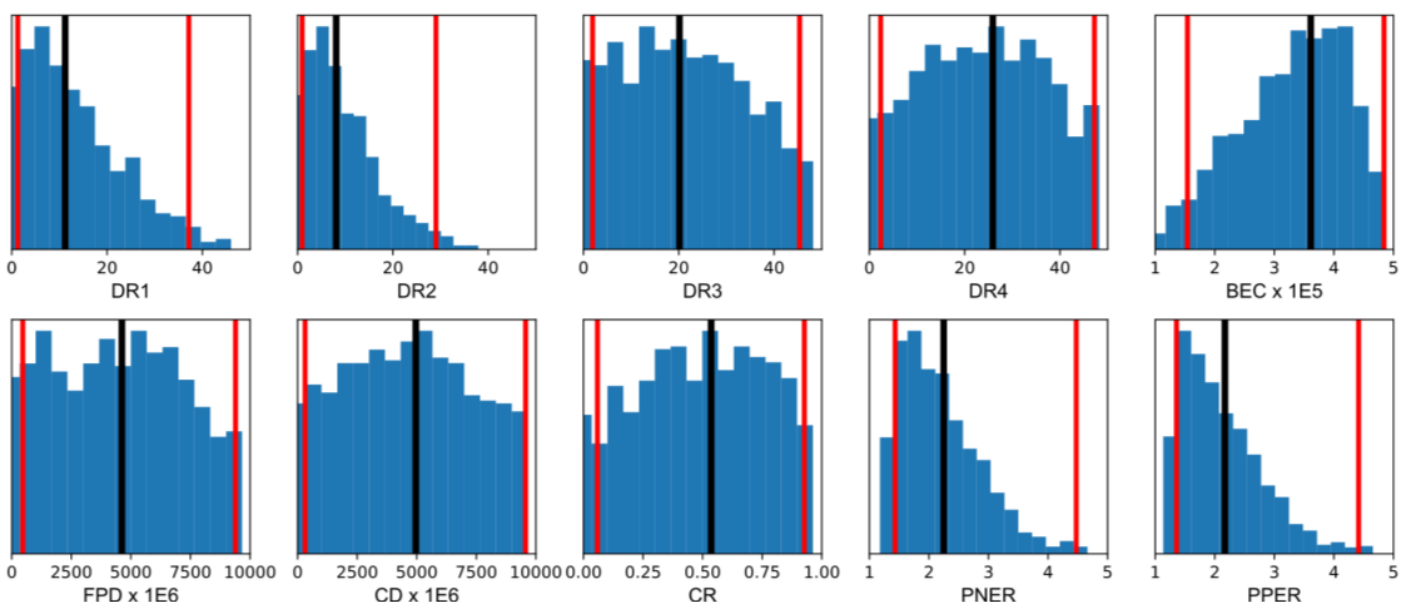

Figure 3. Histograms of SMC-ABC posterior marginal parameter distributions of the water quality model. The vertical black lines indicate the location of the distribution mean and the red lines represent the $95 \%$ confidence intervals. Table 1 provides a description of the parameters. 
Baheerathan et al., Calibration of Great Barrier Reef catchment water quality models

The summary statistic chosen for the SMC-ABC parameter inference and uncertainty analysis was

$$
S(\boldsymbol{y})=\sqrt{a \cdot S E D_{\% \text { bias }}^{2}+b \cdot P N_{\% \text { bias }}^{2}+c \cdot P P_{\% \text { bias }}^{2}}
$$

where $S E D_{\% \text { bias }}, P N_{\% \text { bias }}$ and $P P_{\% \text { bias }}$ are the percent bias of the modelled annual loads of fine sediment, particulate nutrients and particulate phosphorous from the equivalent monitored estimates and $a, b$ and $c$ are weighting coefficients. Automated machine learning surrogate models for each component of the summary statistic where built using a training set of 1000 model evaluations. A Sobol sequence of parameters for the training data was used based on the ranges given in Table 1. The resulting SMC-ABC marginal parameter distributions with $95 \%$ confidence intervals are shown in Figure 3

A 'best' model was chosen using a set of parameters based on the expectation values of their respective marginal parameter distributions. Calibrated fine-sediment streambank erosion along the O'Connell River and average annual fine-sediment loads at the Pioneer River and Sandy Creek EOS sites are compared against that estimated by the ORSA and GBRCLMP to assess the performance of the calibration method.

\subsection{Stream bank erosion along the O'Connell River}

Table 2. LIDAR derived and modelled predicted fine-sediment streambank erosion volumes along the O'Connell River including the lower and upper 95\% confidence limits from model parameter uncertainties.

\begin{tabular}{|l|c|c|c|c|}
\hline & \multicolumn{4}{|c|}{ Fine-sediment streambank erosion $\left(\mathbf{m}^{\mathbf{3}}\right)$} \\
\hline & ORSA & Model & $\mathbf{9 5 \%}$ LCL & $\mathbf{9 5 \%}$ UCL \\
\hline Reach - 1 & 80,410 & 86,732 & 44536 & 129202 \\
\hline Reach - 2 & 6,460 & 3,281 & 1,684 & 4,887 \\
\hline Reach - 3 & 21,000 & 21,485 & 11,032 & 32,005 \\
\hline Reach - 4 \& 5 & 27,360 & 21530 & 11,057 & 32,073 \\
\hline Total & $\mathbf{1 3 5 , 2 3 0}$ & $\mathbf{1 3 3 , 0 2 7}$ & $\mathbf{1 0 0 , 1 1 1}$ & $\mathbf{1 6 6 , 3 6 5}$ \\
\hline
\end{tabular}

Table 2 summarises fine-sediment streambank erosion estimates by the calibrated model along the O'Connell River and its reaches (between 2010 and 2014) against that calculated from the ORSA estimates. The emergent model results for the effective streambank erosion volumes are encouraging with the calculated total erosion over the 5 year period being within $2 \%$ of the empirically based estimate.

\subsection{GBRCLMP and modelled EOS loads}

Table 3 compares average annual fine-sediment and particulate nutrient loads estimated by the calibrated model at the Pioneer River and Sandy Creek EOS sites against GBRCLMP estimates.

Table 3. Monitored and modelled average annual fine-sediment and particulate nutrient loads at EOS sites including the lower and upper $95 \%$ confidence limits from model parameter uncertainties.

\begin{tabular}{|c|c|c|c|c|c|}
\hline EOS sites & Water quality constituents & GBRCLMP & Model & 95\% LCL & 95\% UCL \\
\hline \multirow{3}{*}{ Pioneer River } & Fine-sediments (kt/year) & 189,218 & 189,368 & 182,282 & 196,194 \\
\cline { 2 - 6 } & Particulate nitrogen (t/year) & 641 & 695 & 617 \\
\cline { 2 - 6 } & Particulate phosphorus (t/year) & 193 & 209 & 22,831 \\
\hline \multirow{3}{*}{ Sandy Creek } & Fine-sediments (kt/year) & 25,542 & 25,109 & 27,830 \\
\cline { 2 - 6 } & Particulate nitrogen (t/year) & 109 & 108 & 79 \\
\cline { 2 - 6 } & Particulate phosphorus (t/year) & 37 & 36 & 28 \\
\hline
\end{tabular}

The model has satisfactorily recovered the particulate constitute loads and, in all cases, the GBRCLMP results lie well within the model's 95\% confidence intervals. For both the Pioneer and Sandy Creek catchments, modeled average annual fine sediment loads are reproduced within $2 \%$ of the results derived from monitoring activities. Modelled particulate nutrient loads for the Pioneer system deviate from the GBRCLMP results by 
around $9 \%$ suggesting that the using the same nutrient enrichment ratios for both catchments may not justified but the observational data are still well enveloped by the $95 \%$ confidence intervals.

\section{DISCUSSION AND CONCLUSIONS}

In this study, SMC-ABC and machine learning trained surrogate models were used for the calibration and uncertainty analyses of GBR water quality model parameters.

The comparison between calibrated fine-sediment streambank erosion along the O'Connell River between 2010 and 2014 against that estimated by the O’Connell River stability assessment was encouraging. The calibrated estimate was only $1.5 \%$ lower than the ORSA estimate. Total fine-sediment streambank erosion is likely to have been higher than the ORSA estimate because the ORSA did not include sediment release from minor erosion sites, due to uncertainties associated with identifying minor streambank erosion sites in the DOD developed using the repeat LiDAR datasets.

The calibrated average annual fine-sediment and particulate nutrient loads at the Pioneer River EOS site is within $9 \%$ of that estimated by the GBRCLMP. Average annual fine-sediment and particulate nutrient loads estimated by the calibrated model at Sandy Creek EOS site is within $\pm 2 \%$ of that estimated by GBRCLMP.

This work demonstrates that employed together, SMC-ABC and machine-learning trained surrogate models offer an efficient, well suited framework for the calibration and uncertainty, analyses of GBR water catchment quality model parameters. Further work on this concept will investigate the choice of summary statistics for $\mathrm{ABC}$ as well as extending the methodology for the study of other GBR catchments.

\section{ACKNOWLEDGMENTS}

This project is funded by the Australian and Queensland governments' Paddock to Reef program.

\section{REFERENCES}

Anon (2018) Reef 2050 Long-Term Sustainability Plan-July 2018. Commonwealth of Australia.

Bennett, F.R. (2019) Gradient boosting machine assisted approximate Bayesian computation for uncertainty analysis of rainfall-runoff model parameters. Canberra, Australia: .

Cui, T., Peeters, L., Pagendam, D., Pickett, T., Jin, H., Crosbie, R.S., Raiber, M., Rassam, D.W. and Gilfedder, M. (2018) Emulator-enabled approximate Bayesian computation (ABC) and uncertainty analysis for computationally expensive groundwater models. Journal of Hydrology 564, 191-207.

Ellis, R.J. (2017) Dynamic SedNet Component Model Reference Guide: Update 2017, Concepts and algorithms used in Source Catchments customisation plugin for Great Barrier Reef catchment modelling. Bundaberg, Queensland, Australia: Queensland Department of Science, Information Technology, Innovation and the Arts.

Ivesich, M., Hardie, R. and Blackham, D. (2014) O’Connell River Stability Assessment. Final ReportMackay: Alluvium.

McCloskey, G.L., Waters, D., Baheerathan, R., Darr, S., Dougall, C., Ellis, R., Fentie, B. and Hateley, L. (2017) Modelling pollutant load changes due to improved management practices in the Great Barrier Reef catchments: updated methodology and results - Technical Report for Reef Report Cards 2015. Brisbane, Queensland: Queensland Department of Natural Resources and Mines.

Nott, D.J., Marshall, L. and Brown, J. (2012) Generalized likelihood uncertainty estimation (GLUE) and approximate Bayesian computation: What's the connection?: TECHNICAL NOTE. Water Resources Research 48 (12), .

Olson, R.S., Urbanowicz, R.J., Andrews, P.C., Lavender, N.A., Kidd, L.C. and Moore, J.H. in G Squillero \& P Burelli (editors), (2016) Automating Biomedical Data Science Through Tree-Based Pipeline Optimization. Applications of Evolutionary Computation Springer International Publishing123-137.

Sadegh, M. and Vrugt, J.A. (2013) Bridging the gap between GLUE and formal statistical approaches: approximate Bayesian computation. Hydrology and Earth System Sciences 17 (12), 4831-4850.

Toni, T., Welch, D., Strelkowa, N., Ipsen, A. and Stumpf, M.P.H. (2009) Approximate Bayesian computation scheme for parameter inference and model selection in dynamical systems. Journal of The Royal Society Interface 6 (31), 187-202.

Turner, R., Huggins, R., Wallace, R., Smith, R. and Warne, M.S.J. (2013) Total suspended solids, nutrient and pesticide loads (2010-2011) for rivers that discharge to the Great Barrier Reef. Brisbane: Department of Science, Information Technology, Innovation and the Arts. 